\title{
Siirt İli Florasında Doğal Olarak Yetişen Salvia multicaulis Vahl.’ in Uçucu Yağ Kompozisyonunun Belirlenmesi
}

\author{
Doğan Arslan ${ }^{1 *}$, Mehmet Fidan ${ }^{2}$ \\ ${ }^{1}$ Siirt Ünivesitesi Ziraat Fakültesi Tarla Bitkileri Bölümü Kezer Kampüsü Siirt/Türkiye (ORCID: 0000-0001-7156-5269) \\ ${ }^{2}$ Siirt Ünivesitesi Fen Edebiyat Fakültesi Biyoloji Bölümü Kezer Kampüsü Siirt/Türkiye (ORCID: 0000-0002-0255-9727)
}

(İlk Geliş Tarihi 22 Ocak 2020 ve Kabul Tarihi 22 Şubat 2020)

(DOI: 10.31590/ejosat.678479)

\begin{abstract}
ATIF/REFERENCE: Arslan, D. \& Fidan, M. (2020). Siirt İli Florasında Doğal Olarak Yetişen Salvia multicaulis Vahl.' in Uçucu Yağ Kompozisyonunun Belirlenmesi. Avrupa Bilim ve Teknoloji Dergisi, (18), 196-200.

Öz

Bu çalışma, Siirt ili florasında doğal yayılıı̧ gösteren Salvia multicaulis Vahl.’in uçucu yağ bileşenlerinin belirlenmesi amacıyla yapılmıştır. Çalışmada kullanılan bitki örnekleri 2016 yılında Siirt-Veyselkarani Yolu Gündoğdu Vadisinden toplanmıştır. Uçucu yağ bileşen analizleri Siirt Üniversitesi Bilim ve Teknoloji Uygulama ve Araştırma Merkezi'nde yapılmış ve yağın \% 96.23'ünü temsil eden toplam 19 farklı uçucu yağ bileşeni tespit edilmiştir. Uçucu yağ bileşenlerinin tespiti, GC-MS (gaz kromotografisi-kütle spektrometrisi) cihazı (Thermo Scientific Trace 1310 ve ISQ Single Quadrupole) ile yapılmıştır. Araştırma sonuçlarına göre uçucu yağ bileşenleri içerisinde en yüksek orana \%50.96 ile 1.8-Cineole sahip olurken, en düşük orana \%0.21 ile 2-Cyclohexen-1-ol'ün sahip olduğu tespit edilmiştir. 1.8-Cineole'un yanında, Limonene (\%10.25), Caryophyllene oxide (\%9.85), Camphor (\%5.16), Ethylphosphate (\%3.75), $\beta$ Caryophyllene (\%3.01) o-Cymene (\%2.15), Bornylacetate (\%2.14), $\beta$-Pinene (\%2.07), $\beta$-Myrcene (\%2.07) öne çıkan diğer bileşenleri oluşturmuş̧lardır. Salvia multicaulis üzerine yapılan benzer araştırmalarda, farklı bileşenler ile bileşen sayılarının ortaya çıkması toplanan türün farklı standartlarda uçucu yağa sahip olduğunu göstermiştir. Yapılan uçucu yağ bileşen analizine endüstriyel alanda sıklıkla yararlanılan 1.8-Cineole (\%50.96)'ün ana bileşen olduğu tespit edilmiştir.
\end{abstract}

Anahtar Kelimeler: Salvia multicaulis, 1.8-Cineole, Limonene, Caryophyllene oxide, Camphor, Caryophyllene, Cymene.

\section{Determination of Essential Oil Composition of Salvia multicaulis Vahl. Species Growing in Flora of Siirt Province}

\begin{abstract}
This study was carried out to determine the essential oil components of Salvia multicaulis Vahl, which is naturally distributed in the flora of Siirt province. The plant samples used in the study were collected from the Siirt-Veyselkarani road Gündoğdu Valley in 2016. Essential oil component analysis was conducted in Siirt University Science and Technology Application and Research Center and as a result of the essential oil component analysis, a total of 19 different essential oil components were identified. The determination of essential oil components was done with the GC-MS (gas chromatography-mass spectrometer) device (Thermo Scientific Trace 1310 and ISQ Single Quadrupole). According to the results of the research, the highest ratio (50.96\%) of the essential oil components was found to be 1.8-cineol, while the lowest ratio (0.21\%) was found to be 2-cyclohexen-1-ol. Besides 1.8-cineole, limonene (10.25\%), caryophyllene oxide $(9.85 \%)$, camphor $(5.16 \%)$, ethylphosphate $(3.75 \%)$, $\beta$-caryophyllene $(3.01 \%)$ o-cymene $(2.15 \%)$, bornylacetate $(2.14 \%), \beta$-pinene $(2.07 \%)$, and $\beta$-myrcene $(2.07 \%)$ were the other prominent components. In similar studies on Salvia multicaulis the presence of different components the total number of components found varies according to the plant's harvesting location showed that the species collected has essential oils of different standards.
\end{abstract}

Keywords: Salvia multicaulis, 1,8-Cineole, Limonene, Caryophyllene oxide, Camphor, Caryophyllene, Cymene.

\footnotetext{
* Sorumlu Yazar: Siirt Ünivesitesi Ziraat Fakültesi Tarla Bitkileri Bölümü Kezer Kampüsü, Siirt/Türkiye (ORCID: 0000-0001-7156-5269), doganarslan@siirt.edu.tr
} 


\section{Giriş}

Dünyada 236 cins ve 7133 türü ile geniş alanda yayılış gösteren Lamiaceae familyasına (Kubitzki ve ark., 2004) ait en büyük cins yaklaşık 1000 tür ile geniş bir dağılım gösteren Salvia L., cinsidir (Walker and Sytsma, 2007). Lamiaceae familyasına bağlı bitkiler Akdeniz Bölgesi'ndeki iklim koşullarının hâkim olduğu, tropikal ve ılıman bölgelerde yüksek rakımlı düzlüklerde dağılış göstermektedir (Cantino ve ark., 1992). Salvia ise Orta ve Güney Amerika (500 spp.), Bat1 Asya (200 spp.) ve Doğu Asya (100 spp.) olmak üzere üç farklı gen merkezi ile eski ve yeni dünyanın hem tropikal ve hem de 1lıman bölgelerinde yaygın olarak bulunur (Walker and Sytsma, 2007). Türkiye, Salvia için Asya'da önemli bir gen merkezi olup Türkiye'de toplam 97 türünün bulunduğu bildirilmektedir (Kahraman ve ark., 2011).

Sekonder metabolitlerinde ve farmakolojik etkilerinde yüksek çeşitlilik gösteren, dünyada birçok farmakopede yer alan Salvia cinsine ait bitkiler ve bunlara ait olan uçucu yağlar gıda, ilaç, baharat, aromatik, kozmetik ve parfümeri endüstrilerinde kullanılmalarının yanı sıra süs bitkisi olarak da yaygın şekilde değerlendirilirler (Lu and Yeap, 2002; Chalchat, ve ark., 1998; Demirci ve ark., 2003; Imbesi, 1964; Ulubelen, 1964; Perry ve ark., 2003). Bu kadar zengin içeriğe sahip olan ve tıbbi açıdan da önem taşıyan Salvia türlerinin içeriklerinin belirlenmesi bu bitkilerin aydınlatılması içinde önemlidir. Bu sebeple Salvia türlerinin uçucu yăg kompozisyonlarının ve sekonder bileşenlerinin belirlenmesine yönelik hem dünyada hem de Türkiye'de çok sayıda çalışmalar yürütülmüş ve halende yürütülmeye devam etmektedir. (Yılar ve ark., 2017)

Araştırmaya konu olan Salvia multicaulis türü, odunumsu bir rizomdan çıkan, sık dokulu bir örtü oluşturan 12-55 cm boyunda dik gövdeli, dallanmayan çok yıllık otsu formda bir bitkidir. Yaprakları basit, ovat-elliptikten suborbicular'a kadar farklılık göstermektedir. Korolla pembemsi-viyole, nadiren beyaz renklidir. Kayalık, kireçtaşı ve volkanik yamaçlar, şist ve kumlu yamaçlarda 550-2600 m rakımda görülmektedir (Özer, 2016). Kalker ve volkanik kayalıklarının bulunduğu yamaçlar, çakıllı ve kumlu yamaçlar, Quercus çalılıkları, Artemisia stebi, orman açıklıkları bu türün doğal yetişme ortamını oluşturmaktadırlar (Doğan, 2014). Bitkinin çiçek açma dönemi Nisan-Temmuz olup, Türkiye'de kayıtlı olduğu iller; Adana, Batman, Erzincan, Erzurum, Gümüşhane, Hakkâri, Kayseri, Malatya, Siirt, Sivas, Şırnak, Tunceli ve Van'dır (Yapıcı ve ark., 2009; Doğan, 2014).

Salvia multicaulis türünün Türkiye'de birçok yöresel adı vardır. Bunların en çok bilinenleri ise Pune, Kürt Reyhanı, Adaçayı, Çok Dallı Adaçayı. Dağ çayı, Süt otu, Bozkulak, Giyacılık ve Mavi-mor alba'dır (Ekin ve Zorer, 2011; Doğan, 2014; Korkmaz ve Alpaslan, 2014; Furkan, 2016; Baytop, 2007; Tuzlac1, 2007). Türkiye'de, bitkinin toplanma zamanının Mayıs ve Haziran ayları, bitkinin kullanılan kısımlarının ise toprak üstü aksamının olduğu bildirilmektedir (Furkan, 2016; Çakılcığlu ve ark., 2007; Korkmaz ve Karakurt, 2015; Gelse, 2012)

Yemeklerde baharat olarak kullanılan bitkinin toprak üstü aksamları taze ve kuru olarak çay şeklinde demlenip tüketilmektedir. (Baytop, 1999; Korkmaz ve Karakurt, 2015; Özgökçe ve Yılmaz, 2003; Çakılcığlu ve ark., 2007; Furkan, 2016; Gelse, 2012; Karakurt, 2014; Doğan, 2014). Bu çay grip ve soğuk algınlığına karşı kullanılmaktadır (Baytop, 1999; Özgökçe ve Yılmaz, 2003; Korkmaz ve Karakurt, 2015; Furkan, 2016; Karakurt, 2014; Tetik ve ark., 2013).

Yaprakları haricen yara iyileştirici, yanık tedavisinde, iltihap giderici, çıban türü yaralarda iltihabı boşaltmak için, akrep sokmalarına karşı ve şişliklerin tedavisinde kullanılmaktadır (Baytop, 1999; Çakılcıoğlu ve ark., Tuzlacı, 2006; Akgül, 2008; Furkan, 2016; Doğan, 2014).

Bitkinin ayrıca, iştah açıcı, gargara, solunum ve idrar yolları rahatsılıkları, halsizlik, öksürük, midevi, doğal antibiyotik, rahatlatıcı, böbrek taşı için, vücut direncini artırma, boğaz iltihabı, farenjit, bronşit, diyabet, bademcik enfeksiyonu, hazmı kolaylaştırıcı, astım tedavisi, nezle, halsizlik, öksürük, sancı giderici ve sinirleri yatıştırıcı olarak kullanıldığı bildirilmektedir (Yapıcı ve ark., 2009; Korkmaz ve Karakurt, 2015; Akgül, 2008; Furkan, 2016; Karakurt, 2014; Doğan 2014; Cakilcioglu ve Turkoglu, 2010; Bulut, 2006; Tetik ve ark., 2013; Şimşek ve ark., 2002; Akan ve ark., 2008; Gençay, 2007). Ancak, bütün bu yararlarının yanında fazla kullanımı tansiyonun yükselmesine neden olmaktadır (Korkmaz ve Karakurt, 2015).

Toprak üstü kısımları geleneksel halk hekimliğinde kullanımının yanında, yün boyamada değerlendirilir. Kurutularak ve taze olarak hayvan beslemede yem olarak değerlendirilen bitki, sütün içine katılıp sütün daha yoğun kaymak tutması için de kullanılır (Özgökçe ve Y1lmaz, 2003; Akgül, 2008; Doğan, 2014).

S. multicaulis'in belki de en önemli ürünü, çiçekli sürgünlerinden, çiçek ve yapraklarından elde edilen uçucu yağıdır. Elde edilen bu uçucu yağın başlıca bileşenlerinin bornyl asetat, c-karylofilil $\alpha$-pinene, camphor, $\alpha$-copaene, myrtenol, sabinyl acetate, 1,8-cineole, Limonene, borneol olduğu bildirilmiştir (Ahmadi ve Mirza, 1999; Rustaiyan ve ark., 1999; Senatore ve ark., 2004; Morteza-Semnani ve ark., 2005)

Bu çalışmada, Siirt ili doğal yayılış alanından toplanan Salvia multicaulis Vahl.’in uçucu yağ bileşenleri tespit edilmiştir.

\section{Materyal ve Metot}

Bitki örnekleri 2016 yılında Haziran Siirt İli Merkez İlçesi Veyselkarani Yolu Gündoğdu Vadisi’nden (toplamanın yapılıdığı alanın GPS koordinatları: $38^{0} 05^{\prime} 40 . \mathrm{N} \quad 41^{0} 45^{\prime} 59$. E yükseklik 752 m) toplanmıştır. Örneklerden bir tanesi herbaryum tekniklerine göre kurutulmuş ve teşhis yapıldıktan sonra Siirt Üniversitesi Herbaryumu'nda SUFAF1010 nolu herbaryum numarası ile muhafaza altına alınmıştır. Toplanan diğer örnekler ise oda şartlarında kurutularak analizler için uygun koşullarda depolanmıştır. 
Uçucu yağ eldesi, European Pharmacopoeia (2004)' e göre yapılmış olup, 500 mL'lik balonlara 35 gr hava kurusu bitki örneği konulup üzerine $350 \mathrm{~mL}$ saf su eklenmiştir. Ardından Clevenger aparatında 4 saat kaynatılarak uçucu yağ elde edilmiştir. Uçucu yağ bileşenlerinin tespiti ise Thermo Scientific Trace 1310 ve ISQ Single Quadrupole GC-MS (gaz kromotografisi-kütle spektrometrisi) cihazı () ile yapılmış̦tır. Thermo TG-WAX-MS (0,25 mm iç çap * $60 \mathrm{~m}$ uzunlukda, $0,25 \mu \mathrm{m}$ film kalınlığı) kolon kullanılmıştır. Kütle aralı̆̆ $\mathrm{m} / \mathrm{z}$ 50-550 amu olarak ayarlanmıştır. Veri toplamada tarama modu (Scan Mode) kullanılmıștır. MS transfer line sicaklı $\breve{g ̆}^{2} 250$ ${ }^{\circ} \mathrm{C}$, MS iyonizasyon sıcaklığ $250{ }^{\circ} \mathrm{C}$, kolon sıcaklığı başlangıçta $60^{\circ} \mathrm{C}$ olup ve 6 dakika bekletilip, $4{ }^{\circ} \mathrm{C} /$ dak 1 sı artış oranı ile $230{ }^{\circ} \mathrm{C}$ ' ye kadar yükselmiştir. $230^{\circ} \mathrm{C}$ 'de 15 dakika bekletilerek analiz sonuçlandırılmıştır. Her bileşenin tanımlanması Xcalibur programı ile kütle spektrumları kullanılarak (Wiley 9, NIST demo ve mainlib) yapılmıştır.

\section{Araştırma Sonuçları ve Tartışma}

Çalışmada, yapılan analizlerin sonucunda elde edilen uçucu yağ bileșenlerine ait verilere göre uçucu yağın \%96.23'lük kısmını 19 farklı bileşenin oluşturduğu tespit edilmiştir (Tablo 1). Farklı araştırmacılar, dünyanın farklı yerlerinden topladıkları Salvia multicaulis örnekleri ile yaptıkları uçucu yağ bileşen analizleri sonucunda 16 ile 52 arasında farklı bileşen olduğunu bildirmişlerdir (Ahmadi ve Mirza, 1999; Faheda ve ark., 2016; Bagc1 and Kocak, 2008; Mohammadhosseini ve ark, 2008; Rustaiyan ve ark.,1999; Mohammadhosseini, 2015; Morteza-Semnani ve ark., 2005; Mohammadhosseini, 2012). Bitkilerde farklı alanlarda farklı sonuçların çıkmasında ekolojik, iklimsel, bitkinin toplanma döneminin ve metadolojik farklılıkların etkili olduğu düşünülmektedir.

Tablo 1: Salvia multicaulis'e Ait Uçucu Yă̆ Bileşen Tablosu

\begin{tabular}{lcc}
\hline Bileşen Ad1 & Miktar $(\%)$ & RT \\
\hline$\beta$-Pinene & 2.07 & $11: 20$ \\
\hline$\beta$-Myrcene & 2.07 & $13: 11$ \\
\hline Limonene & 10.25 & $14: 49$ \\
\hline 1,8 -Cineole & 50.96 & 14.82 \\
\hline$\rho$-Cymene & 2.15 & 17.22 \\
\hline 1-Octen-3-ol & 1.47 & 23.29 \\
\hline Alpha-copaene & 0.96 & 24.99 \\
\hline Camphor & 5.16 & 26.00 \\
\hline 2-Cyclohexen-1-ol & 0.21 & 27.15 \\
\hline Bornyl acetate & 2.14 & 27.84 \\
\hline$\beta$-Caryophyllene & 3.01 & 28.45 \\
\hline Ethyl phosphate & 3.75 & 30.00 \\
\hline$\alpha$-Caryophyllene & 1.49 & 30.67 \\
\hline Borneol & 1.38 & 31.43 \\
\hline Piperitone & 0.63 & 32.44 \\
\hline Azulene & 0.23 & 32.93 \\
\hline Caryophyllene oxide & 9.85 & 39.41 \\
\hline Humulene epoxide II & 0.54 & 40.82 \\
\hline Alpha-eudesmol & 1.66 & 44.92 \\
\hline Toplam & 99.98 & \\
\hline
\end{tabular}

* Rt (Retention time): Alıkonma süresi (dakika)

Çalışmamızın analiz sonuçlarına göre uçucu yağ bileşenleri içerisinde en yüksek orana \%50.96 ile 1.8-cineole sahip olurken en düşük orana \%0.21 ile 2-Cyclohexen-1- ol'ün sahip olduğu tespit edilmiştir. 1,8-cineole'un yanında, limonene (\%10.25), caryophyllene oxide (\%9.85), camphor $(\% 5.16)$, ethylphosphate $(\% 3.75)$, $\beta$-caryophyllene $(\% 3.01) p$-cymene $(\% 2.15)$, bornylacetate $(\% 2.14), \beta$ pinene (\%2.07), $\beta$-myrcene (\%2.07) öne çıkan diğer bileşenleri oluşturmuşlardır (Tablo 1). Tespit edilen uçucu yağ bileşen sayısının farklılığına rağmen çalışmada tespit edilen bileşenler farklı araştırmacıların tespit ettikleri bileşenler ile benzerlik göstermektedir (Ahmadi ve Mirza, 1999; Faheda ve ark., 2016; Bagcı and Kocak, 2008; Mohammadhosseini ve ark., 2008; Rustaiyan ve ark.,1999; Mohammadhosseini, 2015; Morteza-Semnani ve ark., 2005; Mohammadhosseini, 2012).

\section{Sonuç}

Bu araştırmada Siirt'te doğal yayılış alanından toplanan Salvia multicaulis örneklerinden elde edilen sonuçlara göre uçucu yağda 18 adet bileşen tespit edilmiştir. Tespit edilen bileşenler içerisinde 1.8-cineole, limonene, caryophyllene oxide, camphor öne çıkan bileşenler olmuştur. Salvia multicaulis üzerine yapılan benzer araştırmalarda, farklı bileşenler ile bileşen sayılarının ortaya çıkması ve bu çalışmada da benzer bir sonucun alınması bu türün doğal yayılış gösterdiği alanlarda, dünyanın farklı yerlerinde, farklı standartlarda 
uçucu yağa sahip olduğunu göstermiştir. Ayrıca kültürü yapılmayan türlerin farklı kaliteye sahip olduğunu göstermesi açısından da önemlidir.

Analiz sonuçlarımıza göre uçucu yağda en yüksek oranda tespit edilen bileşen olan 1.8-Cineole (\%50.96) tıbbi açıdan önemli olup (Santos ve ark.,2000; Lee ve ark., 2004; van Vuuren ve Viljoen, 2007; Gomes-Carneiro, 1998), Siirt şartlarında Salvia multicaulis'in kültüre alınması ile 1.8-Cineole üretimi için önemli bir kaynak oluşturubileceği düşünülmektedir.

\section{Kaynakça}

Ahmadi, L., \& Mirza, M. (1999). Essential oil of Salvia multicaulis Vahl. from Iran. Journal of Essential Oil Research, 11, $289-290$.

Akan, H, Korkut, M.M., \& Balos, M.M., (2008). Arat Dağı ve Çevresinde (Birecik, Şanlıurfa) Etnobotanik Bir Araştırma. Fırat Üniversitesi Fen ve Müh. Bil. Dergisi, 20 (1), 67-81.

Akgül, A. (2008). Midyat (Mardin) Civarında Etnobotanik (Yayımlanmamış Yüksek Lisans Tezi). Ege Üniversitesi Fen Bilimleri Enstitüsü, İzmir.

Bagc1, E., \& Kocak, A. (2008). Essential Oil Composition of the Aerial Parts of Two Salvia L. (S. multicaulis Vahl. Enum and $S$. tricochlada Bentham) Species from East Anatolian Region (Turkey). International Journal of Science\&Technology, 3 (1), 13-18.

Baytop, T. (2007). Türkçe Bitki Adları Sözlüğü. Türk Dil Kurumu Yayınları.

Baytop, T. (1999). Türkiye'de Bitkiler ile Tedavi (Geçmişte ve Bugün).

Bulut, Y. (2006). Manavgat (Antalya) Yöresinin Faydalı Bitkileri. (Yayımlanmamış Yüksek Lisans Tezi). Süleyman Demirel Üniversitesi Fen Bilimleri Enstitüsü Biyoloji Anabilim Dalı, Isparta.

Cakilcioglu, U., \& Turkoglu, I. (2010). An Ethnobotanical Survey of Medicinal Plants in Sivrice (Elazıg-Turkey). Journal of Ethnopharmacology. 132, 165-175.

Cantino, P.D., Harley, R.M., \& Wagstaff, S.J. (1992). Genera of Lamiaceae: Status and Classification. In: Harley, R.M. \& Reynolds, T. İçinde: Advances in Labiate Science (sayfa 511-522). Kew: Royal Botanic Gardens.

Chalchat, J.C., Michet, A., \& Pasquier, B. (1998). Study of The Clones of Salvia officinalis L. Yields and Chemical Composition of Essential oil. Flavourand Fragrence Journal. 13, 68-70.

Çakılcıŏ̆lu, U., Türkoğlu, İ., \& Kürşat, M. (2007). Harput (Elâzı̆g) ve Çevresinin Etnobotanik Özellikleri. Doğu Anadolu Bölgesi Araştırmaları (DAUM) Dergisi. 5 (2), 22-28.

Demirci, B., Baser, K. H. C., Yildiz, B., \&Bahcecioglu, Z. (2003). Composition of Essential Oils of Six Endemic Salvia spp. From Turkey. Flavour and Fragrence Journal. 18, 116-121.

Doğan, A. (2014). Pertek (Tunceli) Yöresinde Etnobotanik Araştırmalar. (Yayımlanmamış Doktora Tezi). Marmara Üniversitesi Sağlık Bilimleri Enstitüsü Farmasötik Botanik Anabilim Dalı, İstanbul.

Ekin, Z., \& Zorer Çelebi Ş., (2011). Van Doğal Meralarında Bulunan Bazı Bitkilerin Tıbbi ve Gıda Amaçlı Kullanımının Değerlendirilmesi. Türkiye IX. Tarla Bitkileri Kongresi. (s.,1461-1466). Bursa, Türkiye.

European Pharmacopoeia. (2004). 5th ed.; Council of Europe: Strasbourg Cedex. France, 2004; Vol. I, pp. 217-218.

Faheda, L., Stien, D., Ouainib, N., Eparviera, V., \& El Beyrouthyb, M. (2016). Chemical Diversity and Antimicrobial Activity of Salvia multicaulis Vahl. Essential Chemical Biodiversity. 13, $591-595$.

Furkan, M. K. (2016). Adıyaman İlinde Yetişen Bazı Bitkilerin Etnobotanik Özellikleri. (Yayımlanmamış Yüksek Lisans Tezi). Adıyaman Üniversitesi Fen Bilimleri Enstitüsü Biyoloji Anabilim Dalı, Adıyaman.

Gelse, A. (2012). Adıyaman ve Çevresinin Etnobotanik Özellikleri (Yayımlanmamış Yüksek Lisans Tezi). Yüzüncü Yıl Üniversitesi Fen Bilimleri Enstitüsü Biyoloji Anabilim Dalı, Van.

Gençay, A. (2007). Cizre (Şırnak)'nin Etnobotanik Özellikleri (Yayımlanmamış Yüksek Lisans Tezi). Yüzüncü Yıl Üniversitesi Fen Bilimleri Enstitüsü, Van.

Gomes-Carneiro, M. R., Felzenszwal, I., Paumgartten, F.J.R., (1998). Mutagenicity testing of ( \pm ) -camphor, 1,8-cineole, citral, citronellal, (-)-menthol and terpineol with the Salmonella/microsome assay. Mutation Research. 416, 129-136.

Imbesi, A. (1964). Index Plantarum Quae İn Omnium Populorum Pharmacopies Sunt Adhuc Receptae Confecit. Scilla, Italy: Messanae.

Kahraman, A., Doğan, M., \& Celep, F. (2011). Salvia siirtica sp. nov. (Lamiaceae) from Turkey. Nordic Journal of Botany. 29, 397-401.

Karakurt, E. (2014). Kelkit (Gümüşhane) İlçesinin Etnobotanik Özellikleri. (Yayımlanmamış Yüksek Lisans Tezi). Erzincan Üniversitesi Fen Bilimleri Enstitüsü, Erzincan.

Korkmaz, M., \& Alpaslan, Z. (2014). Ergan Dağı (Erzincan-Türkiye)'nın Etnobotanik Özellikleri, Bağbahçe Bilim Dergisi. 1(3), 1-31. 
Korkmaz, M., \& Karakurt, E. (2015). Kelkit (Gümüşhane) İlçesinde Halk İlacı Olarak Kullanılan Bitkilerin Belirlenmesi Üzerine Etnobotanik Bir Çalışma. Biological Diversity and Conservation. 8 (3), 290-303.

Kubitzki, K. Harley, R.M., Atkins, S., Budantsev, A., Cantino, P.D., Conn, B.J., Grayer, R., Harley M.M., de Kok, R., Krestovskaja, T., Morales, R., Paton, A.J., Ryding, O. \& Upson, T. (2004). Labiatae. İçinde: The Families and Genera of Vascular Plants, (Volume 7, sayfa 167-275). Verlag, Berlin: Springer.Lee B.-H., Annis, P. C., Tumaaliia F., Choi, W.-S. (2004). Fumigant toxicityof essential oils from the Myrtaceae family and 1,8-cineole against 3 major stored-grain insects. Journal of Stored Products Research. 40, 553564.

Lu, Y., \& Yeap, F.L. (2002). Polyphenolics of Salvia a review. Phytochemistry. 59, 117-140.

Mohammadhosseini, M., Pazoki, A., \& Akhlaghi, H. (2008). Chemical Composition of The Essential Oils From Flowers, Stems, and Roots of Salvia multicaulis Growing Wild in Iran. Chemistry of Natural Compounds. 44 (1), 127-128.

Mohammadhosseini, M. (2012). Hydrodistilled Volatile Oils of the Flowers of Salvia leriifolia Bench. and Salvia multicaulis Vahl. As Two Growing Wild Plants in Iran. Asian Journal of Chemistry. 24 (4), 1432-1434.

Mohammadhosseini, M. (2015). Chemical Composition of the Essential Oils and Volatile Fractions from Flowers, Stems and Roots of Salvia multicaulis Vahl. By Using MAHD, SFME and HS-SPME Methods. Journal of Essential Oil Bearing Plants. 18 (6), 1360 1371.

Morteza-Semnani, K., Moshiri, K., \& Akbarzadeh, M. (2005). The essential oil composition of Salvia multicaulis Vahl. from Iran. Journal of Essential Oil Bearing Plants. 8, 6-10.

Özer, H. (2016). Erzurum Çevresinde Doğal Yayılış Gösteren Salvia Türleri ve Tibbi Özellikleri. Tarla Bitkileri Merkez Araştırma Enstitüsü Dergisi. 25 (Özel say1-2):340-345.

Özgökçe, F., \& Yılmaz, G. (2003). Dye Plants of East Anatolia Region (Turkey). Economic Botany. 57 (4), 454-460.

Perry, N., Bollen, C., Perry, E.K., \& Ballard, C. (2003). Salvia for DementiaTherapy: Review of Pharmacological Activity and Pilot Tolerability Clinical Trial. Pharmacology, Biochemistry and Behavior. 75, 651-659.

Rustaiyan, A., Masoudi, S., Monfared, A., \& Komeilizadeh, H. (1999). Volatile Constituents of Three Salvia Species Grown Wild in Iran. Flavourand Fragrance Journal. 14, 276-278.

Santos, F. A. and Rao V. S. N., (2000). Antiinflammatory and Antinociceptive Effects of 1,8-Cineole a Terpenoid Oxide Present in many Plant Essential Oils. Phytotherapy Research. 14, 240-244.

Senatore, F., Arnold, N.A., \& Piozzi, F. (2004). Chemical Composition of The Essential Oil of Salvia multicaulis Vahl. var. simplicifolia Boiss. Growing Wild in Lebanon. Journal of Chromatography A. 1052 (1-2), 237-240.

Şimşek, I., Aytekin, F., Yeşilada, E., \& Yıldııımlı, Ş. (2002). Anadolu'da Halk Arasında Bitkilerin Kullanılış Amaçları Üzerinde Etnobotanik Bir Çalışma. 14. Bitkisel İlaç Hammaddeleri Toplantısı. (sayfa 29-31). Eskişehir, Türkiye.

Tetik, F., Civelek, S., \& Çakılcıŏlu, U. (2013). Traditional Uses of Some Medicinal Plants in Malatya (Turkey). Journal of Ethnopharmacology. 146, 331-346.

Tuzlacı, E. (2007). Dekoratif Türkiye Bitkileri. Alfa Yayınları. İstanbul.

Tuzlacı, E. (2006). Şifa Niyetine Türkiye'nin Bitkisel Halk İlaçları. Alfa Yayınları, 1. Basım.

Ulubelen, A. (1964). Cardioactive andAntibacterial Terpenoids from some Salvia Species. Phytochemisry. 64, 395-399.

van Vuuren, S., F. and Viljoen, A., M., (2007). Antimicrobial activity of limonene enantiomers and 1,8-cineole alone and in combination. Flavour Fragrance Journal. 22: 540-544.

Walker, J. B., \&Sytsma, K. J. (2007). Staminal evolution in the genus Salvia (Lamiaceae): molecular hylogenetic evidence for multiple origins of the staminal lever. Annals of Botany. 100, 375-391.

Yapıcı, Ü.İ., Hoşgören, H., \& Saya, Ö. (2009). Kurtalan (Siirt) İlçesinin Etnobotanik Özellikleri. Dicle Üniversitesi, Ziya Gökalp Eğitim Fakültesi Dergisi. 12: 191-196.

Yılar, M., Kadıŏlu, İ., \& Telci, İ. (2017). Tokat İlinde Doğal Olarak Yetişen Salvia virgata Jacq. ve Salvia candidissima subsp. candidissima Vahl. Bitkilerinin Uçucu Yağ Kompozisyonlarının Belirlenmesi. Turkish Journal of Weed Science. 20(1), 70-77. 